Editorial

\title{
Digital Urban Regeneration and Its Impact on Urban Renewal Processes and Development
}

\author{
Dalit Shach-Pinsly \\ Faculty of Architecture and Town Planning, Technion-Israel Institute of Technology, Israel; E-Mail: dalitsp@technion.ac.il
}

Submitted: 23 September 2021 | Published: 17 November 2021

\begin{abstract}
Urban renewal is one of the main motivations of city regeneration. Urban renewal strategies mainly relate to demolishing old buildings and redeveloping new buildings instead, improving buildings and deteriorated areas, infilling new buildings within existing urban fabric, integrating new communities into old and rolling-down areas, and so on. In parallel to this situation, the modern world is in the wake of the 4th Industrial Revolution, which is characterized by a merger of physical and digital spaces and is consequently affecting cities and their quality of life. Therefore, urban regeneration must take into consideration these digital innovations and harness the emerging technological changes into new development of urban renewal processes and decision-making approaches. This editorial introduces the topic of digital urban regeneration, by discussing possible methodologies and decision-making approaches and presents the thematic issue on "embedding digital technologies into urban renewal processes and development."
\end{abstract}

\section{Keywords}

digital technologies; environment analysis; new models and tools; urban planning and design; urban regeneration; urban renewal; urban technology

\section{Issue}

This editorial is part of the issue "Towards Digital Urban Regeneration: Embedding Digital Technologies Into Urban Renewal Processes and Development" edited by Dalit Shach-Pinsly (Technion-Israel Institute of Technology, Israel).

(C) 2021 by the author; licensee Cogitatio (Lisbon, Portugal). This editorial is licensed under a Creative Commons Attribution 4.0 International License (CC BY).

Over the past decades, mass housing buildings were developed following the post-WWII renewal. Nowadays, these housing buildings are old (50-70 years old) and many do not meet the current construction requirements, such as building materials, small apartment sizes, digital and communication systems, green building standards, earthquake-resistant requirements, infrastructure systems, and so on. Therefore, these buildings do not provide a high quality of life for their residents. Because of the large quantities of these mass housing projects and their spread in many cities around the world, these post-WWII buildings now have major potential for urban regeneration processes (Jeffry \& Pounder, 2016; Kleemann, et al., 2017).

In parallel to this situation, the modern world is in the wake of the 4th Industrial Revolution, which is characterized by a merger of physical and digital spaces and is consequently affecting cities and their quality of life (Jeon \& Suh, 2017). Urban regeneration must take into consideration these digital innovations and harness the emerging technological changes into new development of urban renewal processes and decision-making approaches. Choi and Kim (2017) mention that many cities around the world are preparing to be smart cities via urban regeneration. In addition, these technological changes can also strengthen housing and urban reaction to future pandemic influence, which will improve the urban environment.

There are many topics that must be taken into consideration when integrating digital innovations into urban renewal development. For example, given the existing technology-based tools for assessing various aspects of the built environment, there is a need to understand how to assimilate them into the urban renewal planning process. In addition, there is also the effect of the technological leap on urban renewal development. Over the 
last year and a half, the world has experienced major changes due to Covid-19, including the planning world. Perhaps, this is the great upheaval and change that will cause a major impact for integrating digital innovations into urban renewal development, which underlie the idea of this thematic issue.

This thematic issue joins articles from four continents and 11 countries: Austria, Cyprus, Germany, India, Israel, Latvia, Lithuania, Poland, Taiwan, South Africa, and the United States, bringing together a wide range of research that tie together urban regeneration and digital technologies from different perspectives such as: modern digital planning and ICT; real vs. virtual city planning process; integrating digital twin technology into planning decision making; evaluating urban renewal alternatives based on new digital assessing approaches; integrating smart city methodologies in urban renewal planning process; and digital placemaking and post-pandemic urban regeneration development.

The assembly of articles begins with Shadar's (2021) "Crisis, Urban Fabrics, and the Public Interest: The Israeli Experience," in which the author wonders whether additional urban elements tie together urban fabrics to cope with crises, particularly pandemics, in light of urban planning changes (in practice and theory) over time and demonstrates it in line with the interests of the Israeli state. Shadar (2021) concludes that state interests embodied urban fabrics that integrate community values and proximity to green areas, suitable for individual coping with crises such as the Covid-19 pandemic and proposes viewing these urban elements as suggesting significant involvement of public representatives in future urban renewal efforts.

In their article "Real vs. Virtual City: Planning Issues in a Discontinuous Urban Area in Budapest's Inner City," Benkő et al. (2021) examine whether ICT in urban planning and design can contribute to contemporary neighborhood planning. The authors analyze the transformation of Corvin neighborhood in Budapest and the surroundings of Szigony Street from a new point of view. They conclude that urban planning and development are still essentially based on traditional top-down approaches and digitalizing of planning alone will not solve past planning problems that affect the urban fabric of a neighborhood.

In "Integrating Digital Twin Technology Into Large Panel System Estates Retrofit Projects," Duch-Zebrowska and Zielonko-Jung (2021) analyze urban renewed areas based on the incorporation of digital twin technology into large panel systems in Eastern European countries. Digital twin technology provides feedback on the retrofit of large panel systems at every stage and can be used to increase the level of information and active social participation in projects. Their main goal is to create an open access tool used by diverse design teams from different countries working on separate systems on the same regenerated area, with the exchange of experiences from lessons learnt.
The next two articles relate to the aspect of neighborhood planning evaluation. In "Multiparametric Analysis of Urban Environmental Quality for Estimating Neighborhood Renewal Alternatives," Shach-Pinsly et al. (2021) developed a 3D-GIS multiparametric scenario analysis (including walkability, energy levels, sense of security, water permeability, etc.) for evaluating the performance and quality of the built environment as part of the decision-making process for neighborhood renewal alternatives. The multiparametric analysis is demonstrated on a peripheral neighborhood of low-medium socio-economic status, where there is a significant value for understanding the urban performance of renewed areas. They emphasize the importance that urban renewal processes will harness such models in the decision-making approaches to improve assessment processes and understand future performance of the built environment.

An additional concept for evaluation is demonstrated in "Spatial Accessibility in Urban Regeneration Areas: A Population-Weighted Method Assessing the Social Amenity Provision," by Gutting et al. (2021). They developed a population-weighted accessibility index based on minimal open data for determining the small-scale pedestrian accessibility to basic amenities in urban neighborhoods, demonstrated in four urban regeneration areas in Dresden, Germany. They demonstrated the possibility to map neighborhoods with both high and low population densities and poor and high accessibility to basic services for evaluating neighborhood regeneration measures for future decision-making.

The article "Area-Based Urban Renewal Approach for Smart Cities Development in India: Challenges of Inclusion and Sustainability," by Praharaj (2021), examines the impact of the smart city approach on the spatial design, social, and economic inequities of the urban space by raising a timely question of whether the digital urban renewal strategies, put forward by Indian cities, provide a practical approach for shaping inclusive and sustainable cities. Praharaj's (2021) findings indicate that emphasizing digital urban renewal of selected urban sites, categorized as "smart cities," leads to deepening social polarization, gentrification, and could be a reference for adopting relevant policies and strategies in diverse cities in future planning.

Zgórska et al. (2021), in "Can the Pandemic Be a Catalyst of Spatial Changes Leading Towards the Smart City?," focus on developing a conceptual framework based on two trends affecting current urban development: the influence of Covid-19 on the functionality of urban structures and the notion of "smart cities," both affecting residents' quality of life. Their study shows that the Covid-19 pandemic can become a catalyst of urban change towards the smart city and smart solutions support such changes.

On the same themes of smart city and ICT, Das (2021) in his article "Revitalising South African City Centres Through ICT" investigates whether existing cities in the 
Global South can be revitalized through smart use of $\mathrm{ICT}$, demonstrating it through urban regeneration processes in three South African city centers: Bloemfontein, Port Elizabeth, and Pretoria. His findings indicate that ICT in city centers of Global South countries need significant reinforcement and are not used considerably in many essential city activities, such as monitoring crimes or displaying real-time information in public places that enable city centers to become more vibrant and livable compounds.

In recent years digital placemaking has become an emerging concept. In "Public Space at the 'Palm of a Hand': Perceptions of Urban Projects Through Digital Media," loannou et al. (2021) analyze the impact of digital social media on the perceptions of communities and on placemaking processes, using the case of Nicosia's Eleftheria Square in Cyprus. Their aim is to better understand digital platforms and tools for identifying places and communicate information. The outcomes show that the perceptions of urban projects through digital media are more fluent and not static by constantly updating information and with social media providing a more accurate and updated picture of society's changing perceptions of public space.

In "Digital Placemaking for Urban Regeneration: Identification of Historic Heritage Values in Taiwan and the Baltic States," Shih et al. (2021) provide an interesting overview of the diversity of digital placemaking strategies in three different countries: Taipei (Taiwan), Riga (Latvia), and Kaunas (Lithuania). They map out potential benefits and challenges related to digital placemaking roles in heritage and urban regeneration areas. They developed space-matrixes for placemaking and digital placemaking by identifying defined zones of spatial structure with the highest potential in terms of placemaking or digital placemaking. Spatially, digital placemaking opens up a "hybrid space" between the physical and the digital world, expanding the range of ways a person can experience the surrounding physical space.

Finally, the thematic issue concludes with an article that relates to the Covid-19 pandemic. The Covid-19 era forced the world to move towards the virtual dimension, also for teaching urban regeneration. In "Scanning for Cultural Competency in Online Urban Planning Programs," Garcia (2021) aims at exploring how urban planning/regeneration programs were prepared to deal with the situation inflicted by the Covid-19 pandemic. The article aims at providing the state of the art of online urban planning and regeneration teaching and learning, which is of crucial interest to the planning academic community and think about the way of teaching place-based disciplines with remote teaching and digital tools. He concludes that online urban planning programs must make additional efforts and develop more social collaborative learning, site activities, and visits to overcome the difficulty of understanding communities without site visits and in-person community engagement.

\section{Acknowledgments}

This publication is based upon work from COST Action, European Middle Class Mass Housing (MCMH-EU) CA 18137 supported by COST (European Cooperation in Science and Technology). www.cost.eu

\section{Conflict of Interests}

The author declares no conflict of interests.

\section{References}

Benkő, M., Bene, B., Pirity, Á., Szabó, Á., \& Egedy, T. (2021). Real vs. virtual city: Planning issues in a discontinuous urban area in Budapest's inner city. Urban Planning, 6(4), 150-163.

Choi, C., \& Kim, C. I. (2017). The 4th industrial revolution, smart cities, and sustainable urban regeneration: A perspective study. Journal of Environmental Policy and Administration, 25, 61-91.

Das, D. K. (2021). Revitalising South African city centres through ICT. Urban Planning, 6(4), 228-241.

Duch-Zebrowska, P., \& Zielonko-Jung, K. (2021). Integrating digital twin technology into large panel system estates retrofit projects. Urban Planning, 6(4), 164-171.

Garcia, B. (2021). Scanning for cultural competency in online urban planning programs. Urban Planning, 6(4), 273-282.

Gutting, R., Gerhold, M., \& Rößler, S. (2021). Spatial accessibility in urban regeneration areas: A population-weighted method assessing the social amenity provision. Urban Planning, 6(4), 189-201.

loannou, B., Kalnis, G., \& Nicolaou, L. (2021). Public space at the "palm of a hand": Perceptions of urban projects through digital media. Urban Planning, 6(4), 242-256.

Jeffry, P., \& Pounder, J. (2016). Chapter 5: Physical and environmental aspects. In P. Roberts, H. Sykes, \& R. Granger (Eds.), Urban regeneration (pp. 87-98). SAGE.

Jeon, J., \& Suh, Y. (2017). Analyzing the major issues of the 4th industrial revolution. Asian Journal of Innovation and Policy, 6(3), 262-273.

Kleemann, F., Lederer, J., Rechberger, H., \& Fellner, J. (2017). GIS-based analysis of Vienna's material stock in buildings. Journal of Industrial Ecology, 21(2), 368-380.

Praharaj, S. (2021). Area-based urban renewal approach for smart cities development in India: Challenges of inclusion and sustainability. Urban Planning, 6(4), 202-215.

Shach-Pinsly, D., Bindreiter, S., Porat, I., Sussman, S., Forster, J., \& Rinnerthaler, M. (2021). Multiparametric analysis of urban environmental quality for estimating neighborhood renewal alternatives. Urban Planning, 6(4), 172-188.

Shadar, H. (2021). Crisis, urban fabrics, and the public 
interest: The Israeli experience. Urban Planning, 6(4), 139-149.

Shih, C.-M., Treija, S., Zaleckis, K., Bratuškins, U., Chen, C.-H., Chen, Y.-H., Chiang, C. T. W., JankauskaitèJurevičienè, L., Jūratè, K., Koroḷova, A., Lee, H.-C., Lektauers, A., \& Mlinkauskienè, A. (2021). Digital placemaking for urban regeneration: Identification of his- toric heritage values in Taiwan and the Baltic States. Urban Planning, 6(4), 257-272.

Zgórska, B., Kamrowska-Załuska, D., \& Lorens, P. (2021). Can the pandemic be a catalyst of spatial changes leading towards the smart city? Urban Planning, 6(4), 216-227.

\section{About the Author}

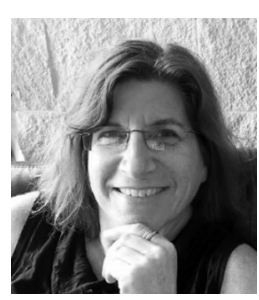

Dalit Shach-Pinsly, PhD, is an architect and urban designer. She is currently a researcher and senior lecturer at the Technion-IIT. She was a partner investigator in the H2020-MG-9.2-2014 MIND-SETSMobility Innovations for a New Dawn in Sustainable Transport Systems. She was a senior researcher of FP7-DESURBS-EU-Designing Safer Urban Spaces. Formerly she joined the College of Built Environments at the University of Washington as a post-doctoral fellow sponsored by the competitive Marie Curie EU IOF Fellowship (2008-2011). 